\title{
Extremely high levels of inbreeding in a natural population of the free-living wasp Ancistrocerus antilope (Hymenoptera: Vespidae: Eumeninae)
}

\author{
THOMAS W. CHAPMAN* \& STEVEN C. STEWART $\dagger$ \\ Department of Biological Sciences, Simon Fraser University, Burnaby, BC, Canada V5A 1 S6 and $\dagger$ Department of \\ Botany, University of Guelph, Ontario, Canada N1G 2W1
}

\begin{abstract}
An isozyme study was conducted on a natural population of the solitary trap-nesting eumenid wasp, Ancistrocerus antilope (Panzer). The inbreeding coefficient was estimated to be 0.757 over seven loci from 322 diploid individuals collected from 108 trap nests. This inbreeding coefficient corresponds to a mixed-mating system with 91.3 per cent of matings occurring between brothers and sisters and the remaining matings occurring randomly. This is the highest inbreeding coefficient yet reported for a free-living Hymenopteran species. If such a high inbreeding level was present in the common ancestor of the Eumeninae and Vespinae, it may have facilitated the evolution of eusociality among the Vespinae.
\end{abstract}

Keywords: diploid males, isozymes, mixed-mating system, sib-mating, social behaviour, trapnesting.

\section{Introduction}

The effects of inbreeding in natural populations include: (i) an excess of homozygous genotypes, such that rare recessive alleles are more directly exposed to natural selection (Hartl, 1971); (ii) facilitation of the evolution of social behaviour (Hamilton, 1964; Wilson, 1975; Michod, 1980; Breden \& Wade, 1991); (iii) the production of female-biased offspring $s \in \mathrm{x}$ ratios, especially among haplodiploid taxa (Herre, 1985); and (iv) the development of diploid males in haplodiploid species with genotypic sex determination (Crozier, 1971). Despite the importance of inbreeding for the genetics and behaviour of haplodiploids and other taxa, few studies have estimated its magnitude in nature.

The absence of inbreeding in social Vespinae suggests that it is not necessary for the maintenance of eusociality, but does not address the question of whether or not inbreeding facilitated the origin of eusocial behaviour. Cowan (1991) has suggested that the strong flying, solitary species of the subfamily of vespid wasps, the Eumeninae, exhibit important preconditions for social evolution because they are closely related to eusocial species of vespid wasps.

${ }^{*}$ Correspondence.
Moreover, behavioural observations indicate that some eumenine species show a high incidence of brother-sister mating (Cowan 1978, 1979, 1986). Cowan $(1978,1979)$ observed brother-sister mating within the species Euodynerus foraminatus and Ancistrocerus adiabatus occurring near trap nests (artificial nesting sites). For example, in E. foraminatus a single male was found to control the natal nest entrance and on average succeeded in mating with 40 per cent of his sisters. Those sisters that did not mate with the dominant brother were seen to vacate the natal nesting area and were assumed by Cowan to mate randomly.

It is presently unknown whether matings that are observed between brother and sister in natural eumenid populations result in viable offspring. Also, matings away from the nesting site are rarely observed and the relatedness of mating pairs is not known. Genetic markers can be used to estimate the inbreeding coefficient and the amount of sib-mating in a population. This technique overcomes the difficulty of tracking wasps to observe their mating behaviour.

Ancistrocerus antilope is a solitary, predatory vespid wasp, an abundant holarctic species belonging to the subfamily Eumeninae (Krombein, 1967; Carpenter \& Cumming, 1985). Its close relationship and 
similar life history to eumenine species that have been observed to sib-mate make it an ideal species to test the hypothesis that sib-mating is occurring in eumenine species. Electrophoretic data from females of this species may be used to estimate the proportion of matings between brothers and sisters. Electrophoretic data can also provide evidence of the frequency of diploid males. This study estimates the mating system of $A$. antilope using electrophoretic gene markers.

\section{Methods}

\section{Organism}

Solitary females of $A$. antilope construct their nests in tunnels in wood that approximate their size in diameter (7-10 mm). Cowan (1978) has demonstrated that females of $A$. antilope will accept simple blocks of wood with holes drilled into them as nesting sites (trap nests).

Wasps were collected from the first of the two generations that occur each year. Voucher specimens are stored with the insect collection at the University of Guelph.

\section{Sampling}

Approximately 1000 trap nests were constructed from $2 \times 2$ spruce strapping cut into $15 \mathrm{~cm}$ lengths. Each cut piece had a $14 \mathrm{~cm}$ long hole drilled into it using a drill bit that was $10 \mathrm{~mm}$ in diameter. Nine trap nests prepared in this manner were bound together using mechanics' wire. A handle was also constructed with the wire and was used to suspend the trap nest bundle from a tree branch. Each nest in a bundle was labelled with one number identifying the bundle and another identifying the individual nest. In the last week of April 1992, trap nest bun- dles were placed in the Arboretum at the University of Guelph. The Arboretum grounds are made up of abandoned farm fields and unmanaged woodland areas. Locations for the trap nests were several metres into the woodland areas from the open fields. Bundles were placed along the field margins every $30 \mathrm{~m}$. The trap nest bundles were placed horizontally, approximately $0.5-1.0 \mathrm{~m}$ from the ground. The nests were monitored every second day until wasps were observed provisioning nests; then observations were made daily. Typically, the nests were observed in the late morning or early afternoon. When a nest entrance was plugged with a mud capping the nest was removed from the bundle and was replaced with an empty trap nest. The date that the nest was collected was written on the nest and it was transported back to the laboratory. Trap nests were stored vertically in cardboard boxes. Plastic pollination bags were placed over the entrances to the nests and secured with a rubber band. Wasps exiting the nest were trapped and could be observed through the pollination bag.

The adult wasps were cooled in a refrigerator $\left(4^{\circ} \mathrm{C}\right)$. The wasps became lethargic and individuals could then be measured for head width. The sex of each individual was also determined.

\section{Electrophoresis}

Starch gel electrophoresis was used to conduct the isozyme study (Table 1).

The buffer systems used were Tris-citrate (TC) (pH 8.0) (Meizel \& Markert, 1967) and Tris-borate (TB) ( $\mathrm{pH}$ 8.6) (Markert \& Faulhaber, 1965). Trisborate gels were run with a $175 \mathrm{~V}$ gradient and a $95 \mathrm{~mA}$ current, Tris-citrate gels with a $115 \mathrm{~V}$ gradient and a $85 \mathrm{~mA}$ current. Polymorphic loci were determined as those loci where the most common allele had a frequency less than 0.95 . The

Table 1 Allele frequencies ( $F, M, S$ - relative electrophoretic mobility) for each polymorphic locus of Ancistrocerus antilope and the inbreeding coefficient $(f)$ with the corresponding amount of sib-mating sufficient to account for this level of inbreeding

\begin{tabular}{lccccccr}
\hline & \multicolumn{3}{c}{ Allele frequencies } & & & & \\
Locus & $F$ & $M$ & $S$ & $\begin{array}{l}\text { Inbreeding } \\
\text { coefficient }\end{array}$ & SE & $\begin{array}{c}\text { Sib-mating } \\
(\%)\end{array}$ & SE \\
\cline { 2 - 7 } Pgm & 0.06 & 0.87 & 0.07 & 0.445 & 0.075 & 0.757 & 0.061 \\
G6pd & 0.06 & 0.79 & 0.15 & 0.645 & 0.046 & 0.878 & 0.022 \\
Gpd1 & 0.30 & 0.49 & 0.21 & 0.704 & 0.074 & 0.903 & 0.032 \\
Got & 0.78 & 0.15 & 0.07 & 0.751 & 0.060 & 0.923 & 0.023 \\
Gpd2 & 0.32 & 0.43 & 0.25 & 0.900 & 0.023 & 0.973 & 0.007 \\
Fes & 0.62 & - & 0.38 & 0.902 & 0.018 & 0.974 & 0.005 \\
Xdh & 0.38 & 0.41 & 0.21 & 0.911 & 0.015 & 0.976 & 0.005 \\
\hline
\end{tabular}


enzyme and buffer systems that showed polymorphisms were: glutamic-oxalacetic transaminase (Got, EC 2.6.1.1) and TC, xanthine dehydrogenase ( $X d h$, EC 1.1.1.204) and TB, phosphoglucomutase (Pgm, EC 5.4.2.2) and TC, glucose-6-phosphate dehydrogenase (G6pd, EC 1.1.1.49) and TC, fluorescentesterase (Fes, EC 3.1.1.1) and TC, glycerol3-phosphate dehydrogenase ( Gpd1 and 2, EC 1.1.1.8) and TB. Five loci were found to be monomorphic: glucose-6-phosphate isomerase (Pgi, EC 5.3.1.9), 6-phosphogluconate dehydrogenase (6Pgd, EC 1.1.1.43), malate dehydrogenase ( $M d h$, EC 1.1.1.37), superoxidase dismutase (Sod, EC 1.15.1.1.) and malic enzyme ( $M e$, EC 1.1.1.40).

\section{Statistical analysis}

Groups of nestmates were collected from trap nests placed in the field. Estimates of population parameters using genotypes from all individuals were expected to be biased because of the close relationship assumed for nestmates. Therefore 108 genotypes (108 trap nests were collected) were sampled by randomly choosing one individual from each group of diploid nestmates (random samples were generated using Microsoft Excel Version 4.0). This sampling procedure was repeated 100 times.

The inbreeding coefficient $(f)$ was calculated as outlined in Weir \& Cockerham (1984). The proportion of sib-mating, $s$, was estimated from the average inbreeding coefficient, $f$, using $s=4 f /(3 f+1)$ (Laidlaw \& Page, 1986). The average inbreeding coefficient and the percentage sib-mating were calculated for each locus over the 100 samples and then across all loci. The variances were determined by jackknifing across all loci (Weir \& Cockerham, 1984). The jackknife is a general-purpose statistical technique useful when the distributional assumptions are not clear (Sokal \& Rohlf, 1981). Statistical results are stated as means and standard deviations.

\section{Results}

\section{Mating system estimate}

The average inbreeding coefficient across loci is $0.757 \pm 0.071(n=7)$ (Table 1). The frequency of matings between brothers and sisters that is sufficient to account for this level of inbreeding is $91.3 \pm 3.0(n=7)$ (Table 1). In two cases, nestmates linked genitalia while trapped in the pollination bags. These matings lasted more than 10 minutes, but the initiation of the mating was not observed for either case.

\section{Sex ratio}

A total of 353 individuals of $A$. antilope emerged from the trap nests. There were 312 females and 41 males (7.6:1 females to males).

\section{Diploid males}

Genotype data were collected for 41 males. Ten males were found to be heterozygous for at least one of the seven polymorphic loci and were deemed to be diploid. Diploid males in other Hymenopteran species have been found to differ in size from haploid specimens (Packer \& Owen, 1990; Mueller et al., 1994). Head width was measured and was assumed to correspond to the general size of individuals. The average head width of females $(0.34 \pm 0.01 \mathrm{~cm})$ was significantly larger than that of males $(0.30 \pm 0.04 \mathrm{~cm})(t=10.89, P<0.0001$, Tukey's test). Males that were determined by electrophoretic analysis to be diploid had an average head width of $0.31 \pm 0.01 \mathrm{~cm}$, not significantly larger than that of haploid males (males which were homozygous at all seven polymorphic loci) which was $0.29 \pm 0.01 \mathrm{~cm}$ (Tukey's test).

\section{Discussion}

The genetic data presented here show that the population of $A$. antilope in the Arboretum near the University of Guelph has a very high inbreeding coefficient, which corresponds to approximately 90 per cent of matings occurring between brothers and sisters. The inbreeding coefficient within this group is higher than in most free-living animal species and approaches the inbreeding coefficients expected in some parasitoid wasps (Waage, 1982). This high level of sibling matings is consistent with observational work undertaken by Cowan $(1978,1979)$ who found that matings in two species of eumenine wasps, Euodynerus foraminatus and Ancistrocerus adiabatus, occur at trap nesting sites between nestmates.

In haplodiploid sex determination systems inbreeding with an associated increase in homozygosity will result in an increase in diploid males (Crozier, 1971) that are sterile or lower in viability than haploid males (Petters \& Mettus, 1980). The number of males in Hymenopteran species that are found to be diploid is often considerably less than 10 per cent and typically only a few specimens are discovered (Crozier, 1971; Kukuk \& May, 1990; Packer \& Owen, 1990). Approximately 25 per cent of males 
electrophoresed were found to be diploid in this population of $A$ antilope, which is consistent with the high inbreeding level.

In Eumeninae, the amount of provisions available to an individual during development is highly correlated with the total adult size of the individual, and females are provisioned more generously than males (Cowan, 1983). If diploid males are provisioned as females it is expected that they would achieve a larger size. Males allocate more resources to quicker development and therefore do not achieve the size of females of the same species (Cowan, 1978). In this population the diploid and haploid male groups were significantly smaller than the females, but dip. loid males were not significantly larger than haploid males.

Artificial nests have proved to be successful in attracting foundresses of many xylophilous aculeate Hymenoptera (Cooper, 1953; Krombein, 1967). The dimensions of the nest have been shown to influence the sex ratio, mating behaviour and the amount of provisions provided by the foundresses for the development of the larvae (Longair, 1981; Danks, 1983; Collins \& Jennings, 1987). The overall sex ratio for this population is strongly biased towards females as Hamilton (1967) predicted for sib-mating arrhenotokous populations. However, the extent of the effect of the artificial trap nest on the population-wide sex ratio is not known, so any estimates of the sex allocation ratio would be difficult to interpret.

Many researchers have invoked inbreeding as an important condition favouring the evolution of sociality (Hamilton, 1964; Wilson, 1975; Michod, 1980; Breden \& Wade, 1991). The observation of sib-mating in two species of eumenine wasps and the genetic data presented in this paper indicating sibmating in a third species (A. antilope) are consistent with the idea that inbreeding is ancestral for Eumeninae + Stenogastrinae + Polistinae + Vespinae, and may be important for the origin of sociality. The Eumeninae are closely related to subfamilies of wasps that exhibit social behaviour: Polistinae and Vespinae (Carpenter, 1982). However, the Stenogastrinae, also a subfamily of vespid wasps, are more closely related to the Polistinae and Vespinae and contain examples of both solitary and social species. Strassmann et al. (1994) point out that the Stenogastrinae probably contain important stages in the evolution of sociality. Investigations of mating systems within this group for solitary and social species could prove informative in further testing of the relationship of mating systems to the evolution of social behaviour.

\section{Acknowledgements}

We thank Bernard J. Crespi, Johnathan Schmidt and John $\mathrm{H}$. Werren for comments on earlier versions of this manuscript. We also thank Allison Back and Yvette Fieg for their technical contributions. This research was funded by an NSERC grant awarded to Steven C. Stewart.

\section{References}

BREDEN, F. AND WADE, M. J. 1991. "Runaway" social evolution: reinforcing selection for inbreeding and altruism. J. Theor Biol., 153, 323-337.

CARPENTER, J. M. 1982. The phylogenetic relationship and natural classification of the Vespoidea (Hymenoptera). Syst. Entomol, 7, 11-38.

CARPENTER, J. M. AND CUMMING, J. M. 1985. A character analysis of the North American potter wasps (Hymenoptera: Vespidae: Eumeninae). J. Nat. Hist., 19, 877-916.

COllins, J. A. AND JENNINGS, D. T. 1987. Nesting height preferences of eumenid wasps (Hymenoptera: Eumenidae) that prey on spruce budworm (Lepidoptera: Tortricidae). Ann. Entomol. Soc. Am., 80, 435-438.

COOPER, K. w. 1953. Biology of eumenine wasps. I. The ecology, predation and competition of Ancistrocerus antilope (Panzer). Trans. Am. Ent. Soc, 79, 13-35.

COWAN, D. P. 1978. Behavior, Inbreeding, and Parental Investment in Solitary Eumenid Wasps (Hymenoptera: Vespidae). Ph.D Thesis, University of Michigan, Ann Arbor, MI.

COWAN, D. P. 1979. Sibling mating in a hunting wasp: adaptive inbreeding? Science, 205, 1403-1405.

COWAN, D. P. 1983. Hypothesis on cell provisioning in eumenid wasps. Biol. J. Linn. Soc., 20, 245-247.

COWAN, D. P. 1986. Sexual behavior of eumenid wasps (Hymenoptera: Eumenidae). Proc. Ent. Soc. Washing. ton, 88, 531-541.

COWAN, D. P. 1991. The solitary and presocial Vespidae. In: Ross, K. G. and Matthews, R. W. (eds) The Social Biology of Wasps, pp. 33-73. Cornell University Press, Ithaca, NY.

CROZIER, R. H. 1971. Heterozygosity and sex determination in haplo-diploidy. Am. Nat., 105, 399-412.

DANKS, H. V. 1983. Differences between generations in the sex ratio of aculeate Hymenoptera. Evolution, 37, 414-416.

HAMILTON, w. D. 1964. The genetical theory of social behaviour, I and II. J. Theor. Biol., 7, 1-52.

HAMILTON, W. D. 1967. Natural selection of unusual sex ratios. Heredity, 22, 163.

HARTL, D. L. 1971. Some aspects of natural selection in arrhenotokous populations. Am. Zool., 11, 309-325.

HERRE, E. A. 1985. Sex ratio adjustment in fig wasps. Science, 228, 896-898.

Krombein, K. V. 1967. Trap-nesting Wasps and Bees: Life 
Histories, Nests, and Associates. Smithsonian Press, Washington, DC.

KUKUL, P. AND MAY, B. 1990. Diploid males in a primitively social bee, Lasiglossum (Dialictus) zephyrum (Hymenoptera: Halictidae). Evolution, 44, 1522-1528.

LAIDLAW, H. H. AND PAGE, R. E., JR 1986. Mating designs. In: Rinderer, T. E. (ed.) Bee Genetics and Breeding, pp. 323-344. Academic Press, New York.

LONGAIR, R. W. 1981. Sex ratio variations in xylophilous aculeate Hymenoptera. Evolution, 35, 597-600.

MARKERT, C. L. AND FAULHABER, L. 1965. Lactate dehydrogenase isozyme patterns of fish. J. Exp. Zool., 159, 319-332.

MEIZEL, S. AND MARKERT, G. L. 1967. Malate dehydrogenase isozymes of the marine snail Ilyanassa obsoleta. Arch. Biochem. Biophys., 122, 753-765.

MICHOD, R. E. 1980. Evolution of interactions in familystructured populations: mixed mating models. Genetics, 96, 275-296.

MUELLER, U. G., EICKWORT, G. C. AND AQUADRO, C. F. 1994. DNA fingerprinting analysis of parent-offspring conflict in a bee. Proc. Nat. Acad. Sci. U.S.A., 91, 5143-5147.

PACKER, L. AND OWEN, R. E. 1990. Allozyme variation, linkage disequilibrium and diploid male production in a primitively social bee Augochlorella striata (Hymenoptera; Halictidae). Heredity, 65, 241-248.

PETTERS, R. M. AND METTUS, R. V. 1980. Decreased diploid male viability in the parasitic wasp, Bracon hebetor. $J$. Hered., 71, 353-356.

SOKAL, R. R. AND ROHLF, F. J. 1981. Biometry, 2nd edn. Freeman, New York.

STRASSMANN, J. E., HUGHES, C. R., TURILlazZI, S., SOls, C. R. AND QUELLER, D. C. 1994. Genetic relatedness and incipient eusociality in stenogastrine wasps. Anim. Behav., 48, 813-821.

WAAGE, J. K. 1982. Sib-mating and sex ratio strategies in scelionid wasps. Ecol. Entomol., 7, 103-112.

WEIR, B. S. AND COCKERHAM, c. C. 1984. Estimating $F$ statistics for the analysis of population structure. Evolution, 38, 1358-1370.

WILson, E. o. 1975. Sociobiology. Harvard University Press, Cambridge, MA. 